\title{
Certain Grain Food Patterns Are Associated with Improved 2015 Dietary Guidelines Shortfall Nutrient Intakes, Diet Quality, and Lower Body Weight in US Adults: Results from the National Health and Nutrition Examination Survey, 2005-2010
}

\author{
Yanni Papanikolaou ${ }^{*}$, Victor L. Fulgoni III ${ }^{2}$ \\ ${ }^{1}$ Nutritional Strategies Inc., Paris, ON, Canada \\ ${ }^{2}$ Nutrition Impact, LLC, Battle Creek, MI, USA \\ Email: "papanikolaou.yanni@gmail.com
}

Received 11 May 2016; accepted 22 July 2016; published 25 July 2016

Copyright (C) 2016 by authors and Scientific Research Publishing Inc.

This work is licensed under the Creative Commons Attribution International License (CC BY).

http://creativecommons.org/licenses/by/4.0/

(c) () Open Access

\section{Abstract}

Objective: The goal of this study was to identify commonly consumed grain food patterns in US adults ( $\geq 19$ years old; $N=14,384$ ) and compare nutrient intakes, with focus on 2015-2020 Dietary Guidelines' shortfall nutrients, diet quality, and health parameters of those consuming various grain food patterns to those not consuming grains. Methods: This study conducted secondary analyses of the National Health and Nutrition Examination Survey, 2005-2010. Cluster analysis was used and identified 8 grain patterns: 1) no consumption of main grain groups, 2) crackers and salty snacks, 3) yeast breads and rolls, 4) cakes, cookies, and pies, 5) cereals, 6) pasta, cooked cereals and rice, 7) quick breads, and 8) mixed grains. Results: Adults consuming "cereals", "pasta, cooked cereals and rice", and "mixed grains" had a better diet quality compared to no grains. Consuming many, but not all, of the grain food patterns resulted in less saturated fat and lower added sugars. Adults consuming "cereals", "pasta, cooked cereals and rice" and "quick breads" had greater dietary fiber intake vs. no grains group. Calcium intake was increased in the cereals group, while magnesium intake was greater in adults consuming "cereals" and "pasta, cooked cereals and rice" vs. no grains. Vitamin D (D2 + D3) intake was higher in adults consuming "cereals", "pasta, cooked cereals and rice", and "mixed grains" vs. no grain group. Adults consuming "pasta, cooked cereals and rice" had lower body weights $(79.1 \pm 0.7$ vs. $82.5 \pm 1.2 \mathrm{~kg} ; P=0.009)$ and waist circumference $(95.2 \pm 0.6$ vs. $98.2 \pm 1.0 \mathrm{~cm} ; P=0.004)$ in comparison to those consuming no grains.

\footnotetext{
${ }^{*}$ Corresponding author.

How to cite this paper: Papanikolaou, Y. and Fulgoni III, V.L. (2016) Certain Grain Food Patterns Are Associated with Improved 2015 Dietary Guidelines Shortfall Nutrient Intakes, Diet Quality, and Lower Body Weight in US Adults: Results from the National Health and Nutrition Examination Survey, 2005-2010. Food and Nutrition Sciences, 7, 772-781.

http://dx.doi.org/10.4236/fns.2016.79078
} 
Conclusions: Certain grain food patterns are associated with greater 2015-2020 Dietary Guidelines' shortfall nutrients, better diet quality and lower body weights in adults. Additionally, certain grain food patterns are associated with lower intake of nutrients to limit, including saturated fat and added sugars.

\section{Keywords}

\section{NHANES, Grain Food Patterns, Nutrient Intakes, Diet Quality, Body Weight}

\section{Introduction}

The 2015-2020 Dietary Guidelines for Americans (2015-2020 Dietary Guidelines) policy report identified that a healthy dietary pattern is higher in fruits, vegetables, whole grains, low- and non-fat dairy, seafood, legumes, and nuts; moderate in alcohol for adults; and lower in red and processed meat, sugar-sweetened foods and beverages and refined grains [1]. Furthermore, in comparison to recommended United States Department of Agriculture (USDA) food patterns, the majority of US adults and children have low intakes of select food groups that are key contributors to shortfall nutrients, including vegetables, fruits, whole grains, and dairy products, while intake of refined grains and added sugars remains higher than recommended [1]. However, a variety of grainbased food products, of which include refined grains, are sources for several shortfall nutrients identified by the 2015-2020 Dietary Guidelines [1], including dietary fiber, folate, iron, and magnesium. With mandatory folic acid fortification commencing in 1998 by the Food and Drug Administration [2], specific grain foods became leading sources for folate; breads, rolls, and crackers are the largest contributor of total folate to the US diet, contributing nearly $16 \%$ of total intake, which exceeds contribution of folate from vegetables [3]. Similarly, using data from the National Health and Nutrition Examination Survey (NHANES) 2003-2006, researchers have reported that fortification substantially contributes nutrient adequacy for children and adolescents in the US, without excessive intakes for most vitamins and minerals [4].

While certain grain food products are rich in nutrients to limit in the diet, including added sugar, total and saturated fat [5] [6], grain foods can contribute positive nutrients to the diet, of which include dietary fiber, iron, magnesium, and B vitamins (thiamin, riboflavin, niacin and folate). A 2003-2006 NHANES analysis examining food sources of energy and nutrients in adults showed that while four of the top ten ranking foods for calorie contribution to the total diet were grain foods, the top ten ranking food sources of dietary fiber included five grain-based products-yeast breads and rolls ranked as the top source of dietary fiber to the diet of US adults, contributing $10.9 \%$ of total dietary fiber [7]. Similarly, researchers have demonstrated that half of the top ten greatest contributors of calories also contribute $10 \%$ or more of the total dietary fiber and micronutrients to the US diet. Indeed, while three of the top 10 sources of energy provided no nutritional value, the remaining sources of energy, including milk, beef, poultry, cheese and baked goods were significant contributors of nutrients of concern and other essential nutrients, and thus, eliminating these foods from food patterns could potentially have inadvertent effects on diet quality in the US population [6].

While 2015-2020 Dietary Guidelines identify several healthy dietary food patterns, and encourage increased whole grain consumption and reduced refined grain intake, at present, there are no data that evaluate the association of different grain food patterns on nutrient and health-related outcomes in adults. As such, the objective of the current analyses was to isolate the most commonly consumed grain food patterns in US adults and compare nutrient intakes, diet quality, and health parameters of those consuming various grain food patterns to those not consuming main grain foods using data from several National Health and Nutrition Examination Survey (NHANES) 2005-2010 datasets. The hypothesis for the present analysis was that certain grain food patterns can significantly contribute positive nutrients, while concurrently lowering nutrients to limit in the diet. Additionally, we hypothesized that certain grain food patterns would be associated with improved measures on health parameters including body weight and overweight or obesity-related outcomes.

\section{Subjects and Methods}

Data were obtained from What We Eat in America, the dietary intake component of NHANES. NHANES is a 
government-directed program led by the Center for Disease Control and Prevention in collaboration with USDA. Written informed consent was obtained for all participants or proxies, and the survey protocol was approved by the Research Ethics Review Board at the National Center for Health Statistics. Data from the current NHANES analysis are released every two years; for this study three data releases were used, namely 2005-2006, 20072008, and 2009-2010 [8] [9].

Data from the first 24-hr dietary recall in NHANES were used, which was an in-person conducted assessment with trained specialists using the best methods developed to date (i.e., the multiple pass method was developed and validated, at least in adults, by the USDA), with all foods and beverages consumed in the last 24 hour period recorded. USDA's Food and Nutrient Database for Dietary Studies, 3.0, 4.1, and 5.0 was used to code dietary intake data and calculate nutrient intakes [10]-[12].

To develop patterns of grain consumption we used cluster analyses which is a statistical procedure that analyses large data sets to develop various patterns while trying to maximize differences among the patterns. We used the USDA food coding system to define categories of grain foods [12].

Grain foods intake patterns were identified using SAS 9.4 (SAS Institute, Cary, NC, 2013) PROC CLUSTER using a single 24-hour dietary recall in NHANES 2005-2010 and applying population weights to adjust for the complex design. Clusters were developed based on the percentage of calories consumed from the grain products as the centroid for each cluster. Grains from flour and dry mixes, mixed dishes, and meat substitutes were not included in development of grain clusters. Cluster analyses provides the ability to focus on a particular defined aspect (e.g. calories from grains) and then forces maximal differences in clusters for assessment.. For these analyses, the USDA grains products were collapsed into the grain food groupings mentioned above. All food codes fit in one and only one of the grain foods groupings. The patterns identified by the cluster analysis were then identified by percent calories within each grain food grouping (only groups that contributed 5\% or more of calories were used to define the clusters) at the centroid of each cluster. Using this method resulted in seven readily identifiable grain food patterns and a no consumption of main grain groups (i.e., no grains group); creating eight unique patterns of consumption. With grain foods patterns identified, and using the output from the cluster procedure, each subject was then placed in the cluster that matched most closely to the pattern of calories across the food categories.

Adjusted mean values were determined for subjects in each cluster using PROC REGRESS in SUDAAN 11.0 with various sets of covariates. Covariates for analyses of energy intake, Healthy Eating Index (HEI)-2010 and HEI sub-components [13] were age, gender, ethnicity, poverty income ratio, physical activity (sedentary, moderate or vigorous based on questionnaire responses), current smoking status, and alcohol intake. The HEI provides a measure of diet quality and conforms to federal dietary guidance and has been predominantly used to monitor dietary practices of the US population and the low-income subpopulation. Nutrient intakes were also adjusted for energy intakes. For body weight, body-mass index (BMI), and waist circumference, covariates were the same as those for energy intake. All other physiological variables had the same covariates but were also adjusted for BMI. The main comparison of interest was to compare results between the no grains group (cluster 0 ) and all other clusters. To increase the rigor of the analyses, a P-value of $\mathrm{P}<0.01$ was set for significance in place of the traditional value of $\mathrm{P}<0.05$.

\section{Results}

Eight grain clusters were identified, one of which included isolating a group of adults that did not consume any of the identified grains (5.8\% of the population). The eight clusters were defined as outlined in Table 1 , namely: 1) no consumption of main grain groups, 2) crackers and salty snacks, 3) yeast breads and rolls, 4) cakes, cookies, and pies, 5) cereals, 6) pasta, cooked cereal and rice, 7) quick breads, and 8) mixed grains.

\subsection{Energy and Nutrient Intakes}

Nutrient and energy intakes in the eight grain food patterns are presented in Table 2. In adults, energy intake was significantly higher in those in all clusters as compared to individuals in the no grains cluster. The higher energy intake ranged from 340 to $567 \mathrm{kcal} / \mathrm{d}$ with mixed grains cluster representing the greatest increase in kcal/day (Table 2).

When examining nutrients of concern, as outlined by the 2015 DGAC [16], calcium intake was higher in adults consuming “cereals” as compared to those not consuming grain foods, while dietary fiber was higher in 
Table 1. Grain cluster pattern based on percentage of calories from grains in adults $\geq 19$ years old of age using data from NHANES 2005-2010.

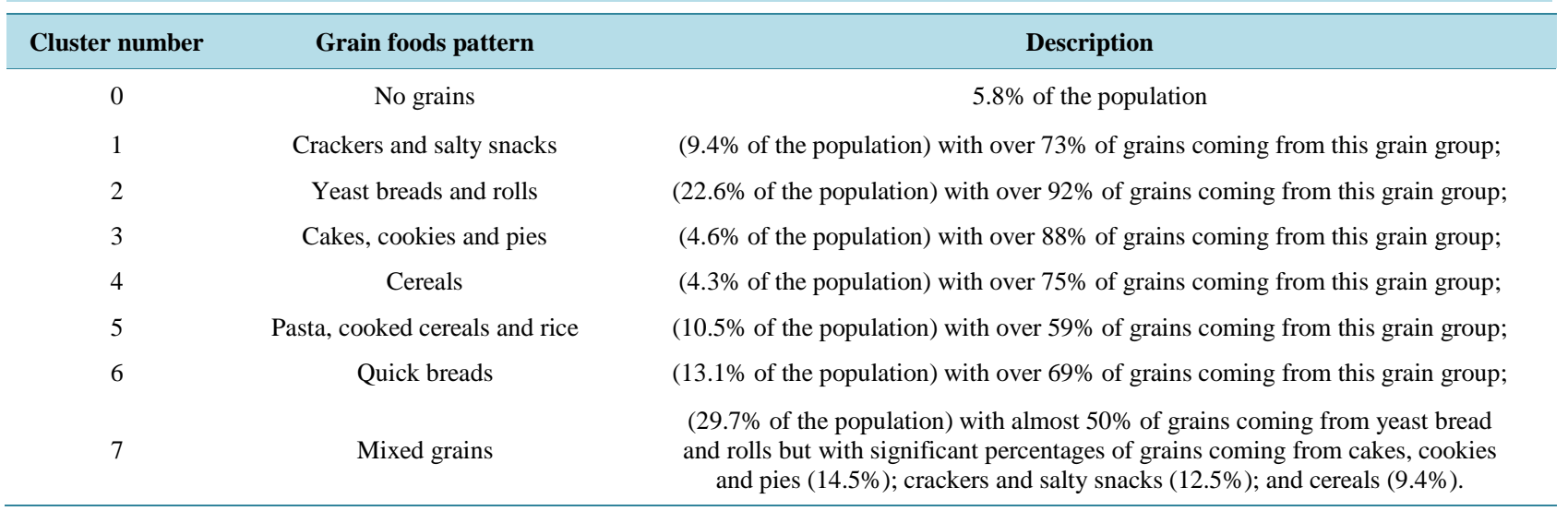

Table 2. Adjusted Mean (SE) nutrient and energy intake for all grain clusters using NHANES 2005-2010, $\geq 19$ years of age.

\begin{tabular}{|c|c|c|c|c|c|c|c|c|c|c|c|c|c|c|c|c|c|c|c|c|c|c|c|}
\hline \multirow{3}{*}{ Energy or Nutrient } & \multirow{2}{*}{\multicolumn{2}{|c|}{$\begin{array}{c}\text { No Grains } \\
\text { Cluster } 0\end{array}$}} & \multicolumn{3}{|c|}{$\begin{array}{c}\text { Crackers/Salty } \\
\text { Snacks }\end{array}$} & \multicolumn{3}{|c|}{$\begin{array}{l}\text { Yeast Breads } \\
\text { and Rolls }\end{array}$} & \multicolumn{3}{|c|}{ Cakes/Cookies/Pies } & \multicolumn{3}{|c|}{ Cereals } & \multicolumn{3}{|c|}{$\begin{array}{c}\text { Pasta/Cooked } \\
\text { Cereals/Rice }\end{array}$} & \multicolumn{3}{|c|}{ Quick Breads } & \multicolumn{3}{|c|}{ Mixed Grains } \\
\hline & & & & Clust & er 1 & & Cluste & er 2 & & Clust & er 3 & & Cluste & ter 4 & & Clust & er 5 & & Cluste & ter 6 & & Clust & ter 7 \\
\hline & LSM & SE & LSM & I SE & $\mathbf{P}$ & LSM & SE & $\mathbf{P}$ & LSM & I SE & $\mathbf{P}$ & LSM & SE & $\mathbf{P}$ & LSM & I SE & $\mathbf{P}$ & LSM & SE & $\mathbf{P}$ & LSM & SE & $\mathbf{P}$ \\
\hline Energy (kcal) & 1715 & 44.9 & 2226 & 43.3 & $<0.0001$ & 2055 & 17.7 & $<0.0001$ & 2244 & 54.1 & $<0.0001$ & 2080 & 51.3 & $<0.0001$ & 2069 & 21.4 & $<0.0001$ & 2247 & 27.2 & $<0.0001$ & 2282 & 23.2 & $<0.0001$ \\
\hline Carbohydrate (g) & 247 & 2.73 & 257 & 3.01 & 0.0184 & 247 & 1.58 & 0.9120 & 265 & 3.22 & $<0.0001$ & 276 & 2.74 & $<0.0001$ & 271 & 2.08 & $<0.0001$ & 257 & 2.22 & 0.0028 & 264 & 1.38 & $<0.0001$ \\
\hline Total sugars (g) & 125 & 2.63 & 112 & 2.40 & 0.0007 & 113 & 1.84 & $<0.0001$ & 141 & 3.57 & 0.0005 & 128 & 2.71 & 0.3916 & 115 & 1.97 & 0.0005 & 109 & 1.50 & $<0.0001$ & 121 & 1.33 & 0.2127 \\
\hline $\begin{array}{l}\text { Added Sugar } \\
\text { (tsp eq) }\end{array}$ & 20.1 & 0.79 & 18.1 & 0.53 & 0.0268 & 18.1 & 0.43 & 0.0105 & 24.7 & 0.93 & 0.0001 & 18.5 & 0.67 & 0.0927 & 16.3 & 0.44 & $<0.0001$ & 16.9 & 0.41 & 0.0001 & 19.0 & 0.32 & 0.2091 \\
\hline Protein (g) & 86.1 & 1.16 & 78.0 & 1.18 & $<0.0001$ & 87.4 & 0.62 & 0.2641 & 76.8 & 1.37 & $<0.0001$ & 84.4 & 1.20 & 0.2788 & 86.9 & 1.27 & 0.6445 & 83.9 & 0.92 & 0.1550 & 81.5 & 0.65 & 0.0027 \\
\hline Total fat (g) & 85.6 & 0.96 & 85.2 & 1.17 & 0.7599 & 84.6 & 0.58 & 0.2729 & 82.0 & 1.05 & 0.0090 & 75.1 & 0.96 & $<0.0001$ & 74.7 & 0.70 & $<0.0001$ & 82.0 & 0.84 & 0.0027 & 80.3 & 0.48 & $<0.0001$ \\
\hline $\begin{array}{l}\text { Total saturated } \\
\text { fatty acids (g) }\end{array}$ & 28.8 & 0.49 & 27.4 & 0.43 & 0.0346 & 29.0 & 0.22 & 0.7347 & 26.9 & 0.60 & 0.0096 & 25.5 & 0.50 & $<0.0001$ & 24.0 & 0.27 & $<0.0001$ & 26 & 0.34 & 0.0001 & 26.8 & 0.18 & 0.0002 \\
\hline Cholesterol (mg) & 322 & 13.1 & 259 & 6.75 & 0.0002 & 318 & 5.37 & 0.7112 & 270 & 9.58 & 0.0014 & 224 & 7.04 & $<0.0001$ & 269 & 7.63 & 0.0016 & 307 & 7.89 & 0.3358 & 279 & 4.68 & 0.0034 \\
\hline Dietary fiber (g) & 14.9 & 0.58 & 16.4 & 0.31 & 0.0142 & 14.3 & 0.21 & 0.3176 & 14.1 & 0.46 & 0.3367 & 19.4 & 0.56 & $<0.0001$ & 18.1 & 0.37 & $<0.0001$ & 18.0 & 0.49 & $<0.0001$ & 16.2 & 0.17 & 0.0285 \\
\hline Calcium (mg) & 939 & 23.0 & 937 & 20.9 & 0.9385 & 969 & 11.0 & 0.2604 & 901 & 36.1 & 0.3439 & 1158 & 33.9 & $<0.0001$ & 968 & 17.0 & 0.2624 & 942 & 21.9 & 0.9224 & 987 & 10.6 & 0.0592 \\
\hline Magnesium (mg) & 296 & 7.45 & 301 & 3.45 & 0.4726 & 285 & 2.34 & 0.1488 & 271 & 6.68 & 0.0200 & 335 & 6.69 & 0.0001 & 341 & 4.82 & $<0.0001$ & 308 & 6.70 & 0.1749 & 299 & 2.31 & 0.6764 \\
\hline Iron (mg) & 12.7 & 0.21 & 13.9 & 0.23 & $<0.0001$ & 13.8 & 0.12 & $<0.0001$ & 13.5 & 0.29 & 0.0246 & 23.9 & 0.36 & $<0.0001$ & 17.0 & 0.29 & $<0.0001$ & 15.3 & 0.27 & $<0.0001$ & 16.6 & 0.14 & $<0.0001$ \\
\hline Zinc (mg) & 12.8 & 0.79 & 11.3 & 0.19 & 0.0860 & 11.9 & 0.13 & 0.2950 & 10.7 & 0.25 & 0.0120 & 16.8 & 0.79 & 0.0003 & 12.7 & 0.43 & 0.9290 & 12.4 & 0.39 & 0.6851 & 12.4 & 0.13 & 0.6374 \\
\hline Sodium (mg) & 3590 & 55.9 & 3763 & 53.5 & 0.0187 & 3710 & 29.3 & 0.0437 & 3270 & 62.2 & 0.0003 & 3376 & 46.8 & 0.0036 & 3747 & 46.0 & 0.0386 & 3668 & 28.3 & 0.2201 & 3604 & 21.3 & 0.8104 \\
\hline Folate, DFE (mcg) & 438 & 10.0 & 462 & 10.5 & 0.0796 & 483 & 6.48 & 0.0001 & 467 & 14.4 & 0.0448 & 867 & 21.8 & $<0.0001$ & 615 & 11.9 & $<0.0001$ & 506 & 8.65 & $<0.0001$ & 582 & 8.41 & $<0.0001$ \\
\hline $\begin{array}{c}\text { Riboflavin } \\
\text { (Vitamin B2) (mg) }\end{array}$ & 2.02 & 0.04 & 2.11 & 0.04 & 0.1003 & 2.14 & 0.02 & 0.0084 & 2.01 & 0.05 & 0.8633 & 2.96 & 0.06 & $<0.0001$ & 2.23 & 0.03 & 0.0006 & 2.15 & 0.03 & 0.0132 & 2.32 & 0.02 & $<0.0001$ \\
\hline $\begin{array}{l}\text { Thiamin (Vitamin B1) } \\
\text { (mg) }\end{array}$ & 1.41 & 0.03 & 1.42 & 0.02 & 0.8396 & 1.60 & 0.02 & $<0.0001$ & 1.45 & 0.06 & 0.5113 & 2.15 & 0.04 & $<0.0001$ & 1.75 & 0.02 & $<0.0001$ & 1.63 & 0.03 & $<0.0001$ & 1.78 & 0.03 & $<0.0001$ \\
\hline Total choline (mg) & 349 & 8.08 & 307 & 5.16 & $<0.0001$ & 348 & 3.24 & 0.9160 & 309 & 7.16 & 0.0011 & 314 & 5.83 & 0.0003 & 338 & 5.16 & 0.2753 & 350 & 5.02 & 0.9427 & 328 & 3.21 & 0.0271 \\
\hline $\begin{array}{l}\text { Vitamin A, } \\
\text { RAE (mcg) }\end{array}$ & 575 & 24.9 & 578 & 18.2 & 0.9305 & 557 & 16.5 & 0.5498 & 593 & 29.8 & 0.6365 & 828 & 27.1 & $<0.0001$ & 736 & 23.7 & $<0.0001$ & 601 & 33.8 & 0.5375 & 652 & 10.3 & 0.0086 \\
\hline
\end{tabular}




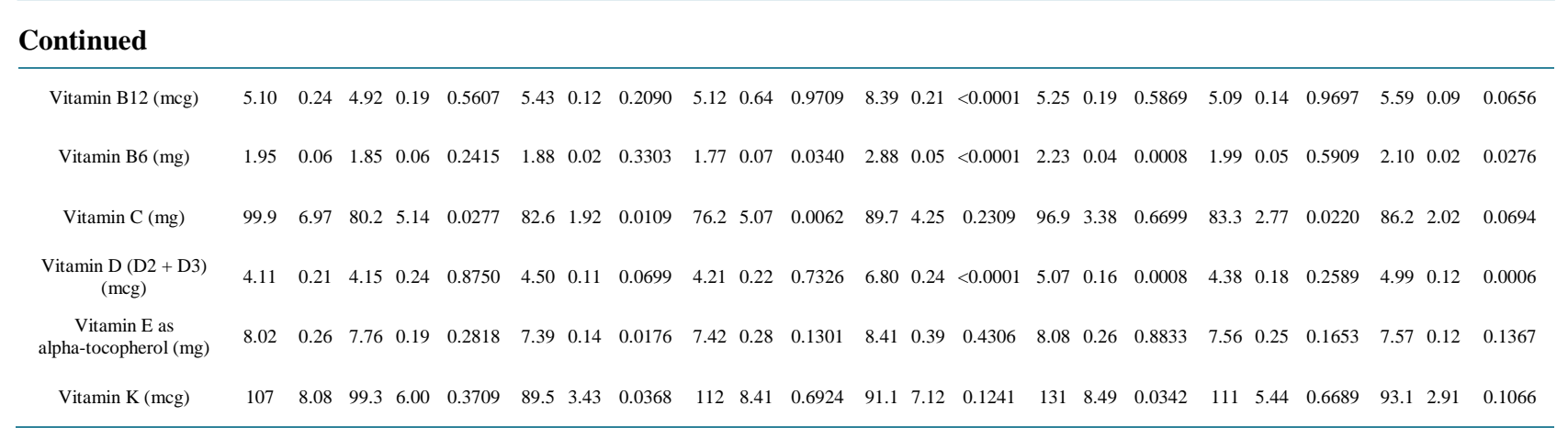

NHANES 2005-2010, $\mathrm{N}$ = 14,384; LSM = least square mean; $\mathrm{SE}$ = standard error; $\mathrm{P}$ = P value of difference as compared to cluster 0 (No grains); Covariates include age, gender, ethnicity, poverty income ratio, physical activity, current smoking status, alcohol and for all variables except Energy, the covariate of energy (kcal).

adults consuming "cereals", "pasta, cooked cereals and rice”, and "quick breads", ranging from 3.1 to 4.5 g/day of increased fiber consumption as compared to those in the no grains group. Vitamin D was greater in those consuming "cereals", "pasta, cooked cereals and rice" and "mixed grains", while potassium was lower in adults consuming "crackers and salty snacks" and "cakes, cookies and pies" as compared to those not consuming grain food products.

Regarding nutrients to limit, total saturated fat intake was reduced in all grain patterns examined, except "yeast breads and rolls" and "crackers and salty snacks" (i.e., the range of saturated fat intake was between 1.9 and $4.8 \mathrm{~g} /$ day lower; see Table 2) and sodium intake was decreased (213 to $319 \mathrm{mg} /$ day) in adults consuming "cakes, cookies and pies" and "cereals" when compared to adults not consuming grain foods. Total sugars were lower (10.3 to 15.9 g/day) in those consuming "crackers and salty snacks", "yeast breads and rolls", "pasta, cooked cereals and rice" and "quick breads", but significantly higher (16.5 g/d) in adults predominantly consuming "cakes, cookies and pies" as compared to those not consuming grain foods. Added sugars were higher ( 4.7 tsp/d) in those consuming "cakes, cookies and pies" and lower in those consuming "pasta, cooked cereals, and rice" and "quick breads" grain patterns (3.8 and 3.1 tsp/d, respectively, see Table 2) in comparison to the no grains group.

Regarding nutrients added to grain foods, via either enrichment or fortification practices, iron intake was greater in adults in all grain cluster food patterns examined except for those consuming "cakes, cookies and pies", while those consuming "yeast breads and rolls", “cereals”, "pasta, cooked cereals and rice”, and "mixed grains" had significantly higher intake of thiamin and riboflavin a as compared to adults not consuming grain foods. Folate was higher (46 to $429 \mu \mathrm{g} / \mathrm{d}$ ) in those in all grain food clusters, except "crackers and salty snacks" and "cakes, cookies and pies", while zinc intake was higher only in adults consuming "cereals" compared to those in the no grains cluster. Magnesium intakes were significantly greater in adults consuming "cereals" and "pasta, cooked cereals and rice" patterns relative to the no grains group (Table 2).

\subsection{Healthy Eating Index-2010}

Diet quality, as measured by USDA's Healthy Eating Index-2010 (HEI-2010) is depicted in Table 3. Adults in the no grain pattern had an HEI score of $46.8 \pm 0.9$. Adults in three of the grain clusters had significantly higher scores relative to the no grains food pattern; adults consuming "cereals" had a HEI score of $54.7 \pm 1.0$, while individuals consuming "pasta, cooked cereals and rice", and "mixed grains" had scores of $54.4 \pm 0.6$ and $49.5 \pm$ 0.3 , respectively (Table 3).

When examining the subcomponents of HEI-2010 (Table 3), and focusing on adults in the "cracker and salty snacks", and "mixed grains" cluster, results showed that those in these grain clusters had significantly lower total vegetable scores than subjects in the no grains pattern. All clusters examined, with the exception of "cereals", had lower scores for refined grains as compared to those not consuming grain foods, suggesting that these individuals consumed greater refined grain products. Adults in the "yeast breads and rolls" and "pasta, cooked cereals and rice" grain cluster also had significantly lower scores for sodium intake relative to adults not consuming grains, suggesting greater daily sodium intake. The lower HEI-2010 sub-component scores for refined grains and sodium were more than offset with increased scores for those in the "cereal", "pasta, cooked cereals and 
Table 3. Adjusted Mean (SE) total Healthy Eating Index-2010 (HEI) and component scores for all grain clusters using NHANES $2005-2010, \geq 19$ years of age.

\begin{tabular}{|c|c|c|c|c|c|c|c|c|c|c|c|c|c|c|c|c|c|c|c|c|c|c|c|}
\hline \multirow{2}{*}{$\begin{array}{l}\text { HEI-2010 } \\
\text { component }\end{array}$} & \multirow{2}{*}{\multicolumn{2}{|c|}{$\begin{array}{l}\text { No grains } \\
\text { Cluster } 0\end{array}$}} & \multicolumn{3}{|c|}{$\begin{array}{c}\text { Crackers/salty } \\
\text { snacks }\end{array}$} & \multirow{2}{*}{\multicolumn{3}{|c|}{$\begin{array}{c}\begin{array}{c}\text { Yeast breads } \\
\text { and rolls }\end{array} \\
\text { Cluster } 2 \\
\end{array}$}} & \multirow{2}{*}{\multicolumn{3}{|c|}{$\begin{array}{c}\begin{array}{c}\text { Cakes/cookies/ } \\
\text { pies }\end{array} \\
\text { Cluster } 3 \\
\end{array}$}} & \multirow{2}{*}{\multicolumn{3}{|c|}{\begin{tabular}{|l} 
Cereals \\
Cluster 4
\end{tabular}}} & \multirow{2}{*}{\multicolumn{3}{|c|}{$\begin{array}{c}\begin{array}{c}\text { Pasta/cooked } \\
\text { cereals/rice }\end{array} \\
\text { Cluster } 5\end{array}$}} & \multirow{2}{*}{\multicolumn{3}{|c|}{$\begin{array}{c}\text { Quick breads } \\
\text { Cluster 6 }\end{array}$}} & \multirow{2}{*}{\multicolumn{3}{|c|}{$\begin{array}{c}\text { Mixed grains } \\
\text { Cluster } 7\end{array}$}} \\
\hline & & & & Cluster & & & & & & & & & & & & & & & & & & & \\
\hline $\begin{array}{c}\text { Total } \\
\text { vegetables }\end{array}$ & 3.25 & 0.10 & 3.00 & 0.06 & 0.0094 & 3.05 & 0.04 & 0.0397 & 2.98 & 0.08 & 0.0236 & 3.02 & 0.07 & 0.0416 & 3.14 & 0.05 & 0.3182 & 3.14 & 0.06 & 0.2508 & 2.91 & 0.03 & 0.0013 \\
\hline $\begin{array}{l}\text { Greens and } \\
\text { beans }\end{array}$ & 1.36 & 0.10 & 1.16 & 0.07 & 0.0747 & 0.96 & 0.06 & 0.0002 & 1.13 & 0.12 & 0.0935 & 1.18 & 0.12 & 0.2801 & 1.62 & 0.09 & 0.0772 & 1.63 & 0.08 & 0.0345 & 1.09 & 0.05 & 0.0128 \\
\hline Total fruit & 1.90 & 0.10 & 1.96 & 0.08 & 0.6105 & 1.99 & 0.06 & 0.4844 & 1.90 & 0.08 & 0.9864 & 2.24 & 0.11 & 0.0281 & 2.48 & $0.06<$ & $<0.0001$ & 1.95 & 0.07 & 0.6589 & 2.27 & 0.05 & 0.0012 \\
\hline Whole fruit & 1.72 & 0.11 & 1.97 & 0.07 & 0.0564 & 1.84 & 0.06 & 0.4080 & 1.94 & 0.09 & 0.1789 & 2.34 & 0.11 & 0.0004 & 2.39 & $0.08<$ & $<0.0001$ & 1.90 & 0.08 & 0.1381 & 2.21 & 0.05 & 0.0001 \\
\hline Whole grains & 0.43 & 0.04 & 2.26 & 0.11 & $<0.0001$ & 1.64 & 0.07 & $<0.0001$ & 0.89 & 0.11 & 0.0009 & 3.64 & 0.18 & $<0.0001$ & 3.66 & $0.17<$ & $<0.0001$ & 1.82 & $0.13<$ & $<0.0001$ & 2.93 & 0.09 & $<0.0001$ \\
\hline Dairy & 4.78 & 0.15 & 5.01 & 0.12 & 0.2514 & 5.16 & 0.10 & 0.0582 & 5.09 & 0.18 & 0.2099 & 6.98 & 0.17 & $<0.0001$ & 4.81 & 0.12 & 0.8806 & 4.85 & 0.12 & 0.7285 & 5.36 & 0.08 & 0.0009 \\
\hline $\begin{array}{l}\text { Total protein } \\
\text { foods }\end{array}$ & 4.10 & 0.08 & 3.88 & 0.06 & 0.0288 & 4.39 & 0.02 & 0.0008 & 3.96 & 0.08 & 0.1949 & 3.79 & 0.08 & 0.0111 & 4.31 & 0.05 & 0.0216 & 4.39 & 0.04 & 0.0033 & 4.20 & 0.03 & 0.2414 \\
\hline $\begin{array}{l}\text { Seafood and } \\
\text { plant protein }\end{array}$ & 1.59 & 0.11 & 2.12 & 0.10 & 0.0010 & 1.94 & 0.06 & 0.0045 & 1.70 & 0.12 & 0.5214 & 1.97 & 0.13 & 0.0334 & 2.29 & $0.08<$ & $<0.0001$ & 2.06 & 0.06 & 0.0007 & 2.00 & 0.06 & 0.0008 \\
\hline $\begin{array}{c}\text { Fatty } \\
\text { acid ratio }\end{array}$ & 4.66 & 0.21 & 5.25 & 0.14 & 0.0145 & 4.26 & 0.07 & 0.0935 & 5.04 & 0.19 & 0.1516 & 4.24 & 0.28 & 0.1720 & 5.34 & 0.11 & 0.0071 & 5.39 & 0.16 & 0.0065 & 4.76 & 0.08 & 0.6424 \\
\hline Sodium & 4.47 & 0.20 & 3.75 & 0.14 & 0.0101 & 3.78 & 0.09 & 0.0007 & 5.35 & 0.14 & 0.0002 & 5.04 & 0.16 & 0.0226 & 3.59 & 0.10 & 0.0003 & 3.97 & 0.08 & 0.0160 & 4.24 & 0.07 & 0.2665 \\
\hline $\begin{array}{l}\text { Refined } \\
\text { grains }\end{array}$ & 7.66 & 0.17 & 5.78 & 0.12 & $<0.0001$ & 6.24 & 0.09 & $<0.0001$ & 7.05 & 0.17 & 0.0034 & 7.32 & 0.20 & 0.2037 & 6.58 & $0.15<$ & $<0.0001$ & 5.00 & $0.11<$ & $<0.0001$ & 6.04 & 0.08 & $<0.0001$ \\
\hline $\begin{array}{l}\text { SoFAAS } \\
\text { calories }\end{array}$ & 10.91 & 0.37 & 11.51 & 0.21 & 0.1929 & 11.74 & 40.20 & 0.0451 & 8.08 & 0.34 & $<0.0001$ & 112.94 & 40.36 & 0.0001 & 14.18 & $80.21<$ & $<0.00011$ & 11.54 & 0.21 & 0.0804 & 11.51 & 0.16 & 0.1391 \\
\hline $\begin{array}{l}\text { HEI-2010 } \\
\text { total score }\end{array}$ & 46.83 & 0.86 & 47.64 & 0.52 & 0.4379 & 46.98 & 30.40 & 0.8744 & 45.09 & 0.65 & 0.0835 & 54.71 & 1.03 & $<0.0001$ & 154.37 & $70.58<$ & $<0.00014$ & 47.65 & 0.53 & 0.3627 & 49.51 & 0.34 & 0.0020 \\
\hline
\end{tabular}

NHANES 2005-2010, $\mathrm{N}=14,384$; LSM = least square mean; SE = standard error; $\mathrm{P}=\mathrm{P}$ value of difference as compared to cluster 0 (no grains); SoFAAS = solid fat, alcohol, added sugars; covariates include age, gender, ethnicity, poverty income ratio, physical activity, current smoking status, and alcohol.

rice” and "mixed grains” clusters for whole fruit, while all grain cluster patterns had significantly higher scores for whole grains as compared to those not consuming grain foods, indicating the contributory value of all grains in helping to reach whole grain recommendations. Additionally, adults consuming "pasta, cooked cereals, and rice” and "mixed grains” had significantly higher scores for total fruit, while all grain clusters except "cereals” and "cakes, cookies and pies", had greater scores for seafood and plant protein in comparison to adults in the no grains pattern. “Cereals”, and "pasta, cooked cereals, and rice” clusters also had significantly greater scores for empty calories (signifying less calories from solid fats, alcohol and added sugars), while those consuming “cakes, cookies and pies” had a greater amount of calories from solid fats, alcohol and added sugars.

\subsection{Physiological Variables}

In adults, body weight and waist circumference were significantly lower (3.5 kg and $3.0 \mathrm{~cm}$, respectively) in those in the "pasta, cooked cereals, and rice" cluster pattern relative to adults in the no grain cluster (body weights: $79.1 \pm 0.7$ vs. $82.5 \pm 1.2 \mathrm{~kg}, \mathrm{P}=0.009$; waist circumference: $95.2 \pm 0.6$ vs. $98.2 \pm 1.0$ cm; $\mathrm{P}=0.004$ ) (Table 4).

Red blood cell folate was higher in those consuming "cereals” (an increase of $76.6 \mathrm{ng} / \mathrm{ml} \mathrm{RBC)} \mathrm{and} \mathrm{"mixed}$ grains” (an increase of $32.5 \mathrm{ng} / \mathrm{ml} \mathrm{RBC)} \mathrm{while} \mathrm{serum} \mathrm{folate} \mathrm{was} \mathrm{higher} \mathrm{in} \mathrm{those} \mathrm{in} \mathrm{the} \mathrm{"cakes,} \mathrm{cookies,} \mathrm{and} \mathrm{pies”,}$ "ereals", and "mixed grains" grain food patterns (range of increase was 2.0 to $4.7 \mathrm{ng} / \mathrm{ml}$ ) relative to adults in the no grain group. HDL cholesterol was significantly lower (a decrease of $3.1 \mathrm{mg} / \mathrm{dL}$ ) in the "cereals” cluster as compared to the no grains cluster, while no differences were seen with LDL-cholesterol across clusters versus the no grains group. There were no differences observed for plasma glucose, plasma insulin, total cholesterol and triglycerides for adults in all clusters when compared to the no grains cluster pattern (Table 4).

\section{Discussion}

This is the first study that has identified various grain food patterns in US adults and documented links between 
Table 4. Adjusted Mean (SE) physiological variables for all grain clusters using NHANES 2005-2010, $\geq 19$ years of age.

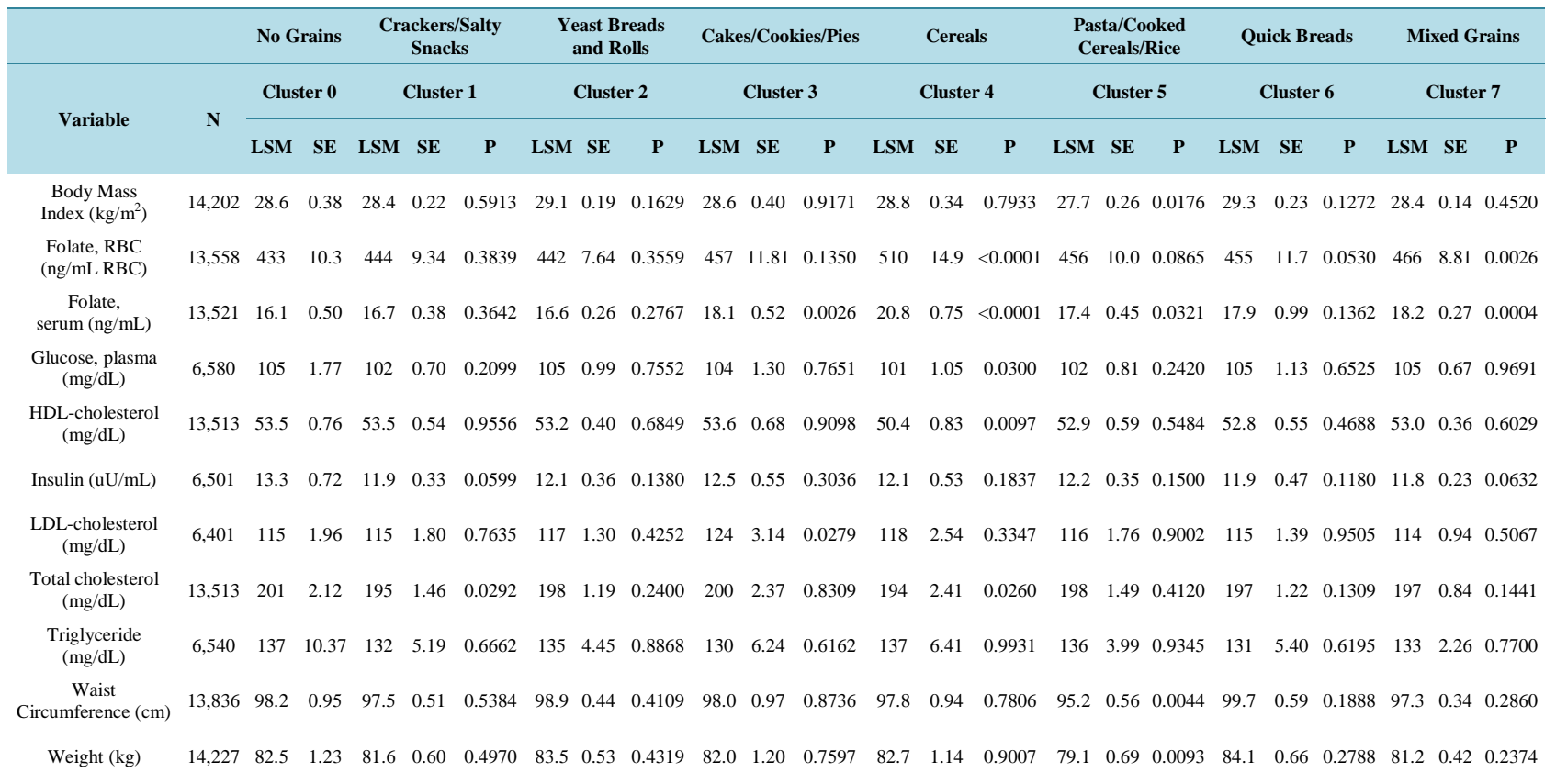

NHANES 2005-2010, $\mathrm{N}=14,384$; LSM = least square mean; $\mathrm{SE}=$ standard error; $\mathrm{P}=\mathrm{P}$ value of difference as compared to cluster 0 (no grains); Covariates include age, gender, ethnicity, poverty income ratio, physical activity, current smoking status, and for non-weight-related variables, the model also includes body mass index.

grain food pattern consumption, nutrient intakes, diet quality and health outcomes. Specifically, certain grain food patterns are associated with greater nutrient intakes, including higher consumption of shortfall nutrients and nutrients of public health concern as identified by the 2015-2020 Dietary Guidelines. Further, adults in the "cereals", "pasta, cooked cereals and rice" and "mixed grains" clusters had improved diet quality as measured by USDA's HEI-2010, relative to those not consuming grain food products. The present observational analysis also found that adults consuming certain grain food patterns have favorable obesity-related outcomes, including lower body weight and a reduced waist circumference. Overall, the present data support several grain food patterns as part of a healthy dietary food pattern, that takes into consideration authoritative recommendations to reduce total fat, saturated fat and added sugar consumption, while concurrently increasing 2015-2020 Dietary Guidelines' shortfall nutrients and/or nutrients of concern, including iron, magnesium, dietary fiber, vitamin D, potassium and folate.

Whole grain cereals and breads have been well-documented in the literature for their role in the prevention of chronic diseases. Regular consumption of whole grain cereals and breads have been linked to lower risk for cardiovascular disease, type 2 diabetes mellitus, and with certain cancers, as discussed in a recent review [14]. Similar to nutrition guidance worldwide, US 2010 dietary recommendations focused on consuming at least half of all grains as whole grains, which is largely a minimum of 3 ounce equivalents per day for most adults, with strong encouragement to increase whole grain consumption by replacing refined grains with whole grains [15], a concept that has been carried forward by the 2015-2020 Dietary Guidelines and the 2015 Dietary Guidelines Advisory Committee (2015 DGAC) [1] [16]. A recent NHANES analysis reported less than 8\% of US adults consumed at least 3 whole grain ounce equivalents per day, while about $50 \%$ of adults consumed $>0$ and $<3$ whole grain ounce equivalents per day, and nearly $42 \%$ reported not consuming any whole grains [17]. Likewise, data stemming from What We Eat in America 2007-2010, showed that the estimated percent of the US population consuming below established whole grain recommendations is greater than $95 \%$ in all children and adults [16]. Coupled with the under consumption of whole grains, the 2015 DGAC [16] concluded "several nutrients are under consumed relative to the Estimated Average Requirement or Adequate Intake levels set by the Institute of Medicine - these shortfall nutrients are vitamin A, vitamin D, vitamin E, vitamin C, folate, calcium, magnesium, fiber, and potassium”. The 2015 DGAC also identified iron to be a shortfall nutrient for adolescent 
and premenopausal females. Similarly, recent work evaluating diet quality based on Denmark’s food-based dietary guidance, identified that while iron intake increased with a better diet quality, mean iron intake in women of childbearing age across all groups examined were below recommended levels, thus suggesting a diet closely aligned to Danish recommendations may still leave many women at risk for inadequate intakes of iron [18]. In the present analyses, iron was significantly higher in adults in all of the grain food patterns examined, while those consuming six of the seven grain food patterns had significantly greater folate intake, ranging from 46 to $429 \mu \mathrm{g}$ per day, relative to those not consuming grain foods. Similarly, magnesium intakes were elevated in adults consuming “cereals” and "pasta, cooked cereals and rice” by 39 and 45 mg per day, respectively, in comparison to adults not consuming grains, representing about $10 \%$ of the Daily Value established for magnesium for adults consuming a $2000 \mathrm{kcal}$ diet.

While previous dietary intake research has reported increased intakes of low-fat dairy products, fish, poultry, rye bread, fruit and vegetables to be associated with a better diet quality and consumption of high-fat dairy products, red and processed meat, white bread, soft drinks, sweets and cakes to be associated with lower diet quality scores, the researchers also noted that added sugar intake and fat on bread were greater in the lowest quartile of the diet quality index and contributed to the high intake of total fat and saturated fat. Collectively, this may represent a meaningful contribution for the lower diet quality outcome and warrants further investigation [18]. Our results are aligned with previous observational findings that considered sources of nutrients in the US diet. When identifying the top food sources of nutrients, including both intrinsic and added to foods via fortification, results showed that grain foods represented the top five ranking food sources for folate, such that readyto-eat cereals, yeast breads and rolls, pizza, pasta and crackers, popcorn, pretzels, and chips contributed 56.7\% and $54.4 \%$ of folate to the diet of children and adolescents, respectively. Similarly, grain foods represented the top five food sources for iron in the diet of US children and adolescents, with ready-to-eat cereals, yeast breads, pizza, cakes, cookies, and pies, and crackers, popcorn, pretzels, and chips cumulatively contributing $52.1 \%$ and $48.7 \%$ of iron [4].

The 2015 DGAC [16] report further states “of the shortfall nutrients, calcium, vitamin D, fiber, and potassium also are classified as nutrients of public health concern because their under consumption has been linked in the scientific literature to adverse health outcomes”, a principle carried forward from the 2010 Dietary Guidelines for Americans policy document [19]. The 2015 DGAC [16] also reports that "if whole grains were consumed in the amounts recommended in the recommended food patterns, whole grains would provide substantial percentages of several key nutrients, such as about 32 percent of dietary fiber, $42 \%$ of iron, $35 \%$ of folate, $29 \%$ of magnesium and $16 \%$ of vitamin A”. While these nutrients levels represent significant contributions from whole grains, whole grain consumption alone can still leave a gap between consumption and recommendation levels. The 2005 Dietary Guidelines Advisory Committee reported that refined grains contribute substantial levels of key nutrients to food patterns, naming folate, iron, calcium, dietary fiber, thiamin, riboflavin and niacin [20]. The committee further acknowledged that including only three ounce equivalents of whole grains daily with no refined grains in recommended food patterns would lower intake of many key nutrients and potentially place specific populations at risk for nutrient inadequacy [20]; an argument which led the 2015 DGAC to conclude that consumption of whole grains with no substitutions would result in nutrient shortfalls [16]. The current analysis provides data linking different grain food patterns with nutrient intakes and concurrently we observed the adverse nutrient- and health-related outcomes when grain foods as a whole are eliminated from the diet. In many of the grain patterns examined, a better nutrient intake profile was observed which demonstrates the important dietary contributions made by different grain foods and emphasizes the importance of consuming whole and refined grains. Indeed, while some of the grain food clusters contributed nutrients to limit in the diet as identified by the 2015 DGAC report [16], including saturated fat, added sugars, and sodium, several of the grain food patterns were associated with lower intakes of these nutrients and improved shortfall nutrient intakes and diet quality. Thus, it is conceivable to rationalize that Americans need more specific dietary guidance about grain consumption rather than simply having two broad categories of recommended intakes that revolve around refined and whole grains.

The present analysis includes limitations inherent in observational research that deserve recognition. Data for energy and nutrient intakes, including values reported for diet quality, were obtained using 24-hour dietary recalls, which rely on study participant memory. While validated procedures are used to collect the data, recalled information may be inaccurate and biased from misreporting, memory challenges and other potential measurement errors experienced in epidemiological research involving large datasets [21] [22]. In addition, the current 
evidence, being observational, cannot establish a causal link between the different grain foods patterns examined and improvements in diet quality, nutrient intakes and other health variables considered. However, a large strength of the current work stems from the use of NHANES, which is a large continuous survey that examines a nationally representative sample of about 5,000 individuals yearly by highly-trained medical personnel [8]. Additionally we used numerous covariates to adjust data in an attempt to remove potential confounding; however residual confounding may still exist that could explain some of the results reported.

\section{Conclusion}

In summary, the consumption of certain grain food patterns in US adults is associated with greater nutrient intakes, including higher consumption shortfall nutrients and nutrients of public health concern as identified by the 2015-2020 Dietary Guidelines [17]. Further, adults in the "pasta, cooked cereals and rice", "cereals", and "mixed grains" dietary patterns had improved diet quality as measured by USDA's HEI-2010, when compared to adults not consuming grain foods. In addition, adults consuming certain grain food patterns have favorable obesity-related health outcomes, including decreased body weights and a reduced risk of having an elevated waist circumference. Overall, while some grain food patterns were associated with elevated sodium and added sugar, the present data also support that several grain food patterns can serve as part of a healthy dietary food pattern that accounts for 2015 Dietary Guidelines recommendations to reduce total fat, saturated fat and added sugar consumption, while concurrently increasing intake of shortfall nutrients and/or nutrients of concern, including iron, magnesium, dietary fiber, vitamin $\mathrm{D}$, potassium and folate.

\section{Acknowledgements}

The current analyses were supported by funding from the Grain Foods Foundation in Washington, DC. YP collaborated on the conception and interpretation of the research and drafted the manuscript. VLF directed the conception and design of the research, conducted the analyses and provided interpretation. Both authors approved the final version of the present manuscript.

\section{References}

[1] United States Department of Health and Human Services and United States Department of Agriculture (2015) 20152020 Dietary Guidelines for Americans. 8th Edition, U.S. Government Printing Office, December.

[2] United States Food and Drug Administration (1996) Food Standards: Amendment of Standards of Identity for Enriched Grain Products to Require Addition of Folic Acid. Federal Register, 61. http://www.gpo.gov/fdsys/pkg/FR-1996-03-05/pdf/96-5014.pdf

[3] Dietrich, M., et al. (2005) The Effect of Folate Fortification of Cereal-Grain Products on Blood Folate Status, Dietary Folate Intake, and Dietary Folate Sources among Adult Non-Supplement Users in the United States. Journal of the American College of Nutrition, 24, 266-274. http://dx.doi.org/10.1080/07315724.2005.10719474

[4] Berner, L.A., et al. (2014) Fortified Foods Are Major Contributors to Nutrient Intakes in Diets of US Children and Adolescents. Journal of the Academy of Nutrition and Dietetics, 114, 1009-1022. http://dx.doi.org/10.1016/j.jand.2013.10.012

[5] Reedy, J. and Krebs-Smith, S.M. (2010) Dietary Sources of Energy, Solid Fats, and Added Sugars among Children and Adolescents in the United States. Journal of the American Dietetic Association, 110, 1477-1484. http://dx.doi.org/10.1016/j.jada.2010.07.010

[6] Huth, P.J., et al. (2013) Major Food Sources of Calories, Added Sugars, and Saturated Fat and Their Contribution to Essential Nutrient Intakes in the U.S. Diet: Data from the National Health and Nutrition Examination Survey (20032006). Nutrition Journal, 12. http://dx.doi.org/10.1186/1475-2891-12-116

[7] O’Neil, C.E., et al. (2012) Food Sources of Energy and Nutrients among Adults in the US: NHANES 2003-2006. Nutrients, 4, 2097-2120. http://dx.doi.org/10.3390/nu4122097

[8] National Health and Nutrition Examination Survey. Analytic and Reporting Guidelines. http://www.cdc.gov/nchs/data/nhanes/nhanes_03_04/nhanes_analytic_guidelines_dec_2005.pdf

[9] National Health and Nutrition Examination Survey. Analytic Note Regarding 2007-2010 Survey Design Changes and Combining Data across Other Survey Cycles. http://www.cdc.gov/nchs/data/nhanes/analyticnote_2007-2010.pdf

[10] United States Department of Agriculture (2008) USDA Food and Nutrient Database for Dietary Studies, 3.0. Agricultural Research Service, Food Surveys Research Group, Beltsville. 
[11] United States Department of Agriculture (2010) USDA Food and Nutrient Database for Dietary Studies, 4.1. U.S. Department of Agriculture, Agricultural Research Service, Food Surveys Research Group, Beltsville.

[12] Ahuja, J.K.A., et al. (2012) USDA Food and Nutrient Database for Dietary Studies, 5.0. United States Department of Agriculture, Agricultural Research Service, Food Surveys Research Group, Beltsville.

[13] Guenther, P.M., et al. (2013) Update of the Healthy Eating Index: HEI-2010. Journal of the Academy of Nutrition and Dietetics, 113, 569-580. http://dx.doi.org/10.1017/S1368980011002576

[14] Gil, A., et al. (2011) Wholegrain Cereals and Bread: A Duet of the Mediterranean Diet for the Prevention of Chronic Diseases. Public Health Nutrition, 14, 2316-2322. http://dx.doi.org/10.1017/S1368980011002576

[15] The Secretary of Health and Human Services and Secretary of Agriculture. United States Department of Agriculture (2010) Scientific Report of the Dietary Guidelines Advisory Committee on the Dietary Guidelines for Americans, 2010. US Department of Agriculture, Washington DC.

[16] United States Department of Agriculture and United States Department of Health and Human Services (USDA/HHS) (2015) Scientific Report of the 2015 Dietary Guidelines Advisory Committee: Advisory Report to the Secretary of Health and Human Services and Secretary of Agriculture. USDA, Agricultural Research Service, Washington DC.

[17] Reicks, M., et al. (2014) Total Dietary Fiber Intakes in the US Population Are Related to Whole Grain Consumption: Results from the National Health and Nutrition Examination Survey 2009 to 2010. Nutrition Research, 34, 226-234. http://dx.doi.org/10.1016/j.nutres.2014.01.002

[18] Knudsen, V.K., et al. (2012) Evaluation of Dietary Intake in Danish Adults by Means of an Index Based on FoodBased Dietary Guidelines. Food \& Nutrition Research, 56, 17129. http://dx.doi.org/10.3402/fnr.v56i0.17129

[19] United States Department of Agriculture and United States Department of Health and Human Services (2010) Dietary Guidelines for Americans, 2010. 7th Edition, U.S. Government Printing Office, December, Washington DC.

[20] The Secretary of Health and Human Services and Secretary of Agriculture. U.S. Department of Agriculture (2005) Scientific Report of the Dietary Guidelines Advisory Committee on the Dietary Guidelines for Americans, 2005. US Department of Agriculture, Washington DC.

[21] Dwyer, J., et al. (2003) Members of the Steering Committee; National Health and Nutrition Examination Survey. Collection of Food and Dietary Supplement Intake Data: What We Eat in America-NHANES. Journal of Nutrition, 133, 590S-600S.

[22] Boeing, H. (2013) Nutritional Epidemiology: New Perspectives for Understanding the Diet-Disease Relationship? European Journal of Clinical Nutrition, 67, 424-429. http://dx.doi.org/10.1038/ejcn.2013.47

\section{Submit or recommend next manuscript to SCIRP and we will provide best service for you:}

Accepting pre-submission inquiries through Email, Facebook, Linkedin, Twitter, etc A wide selection of journals (inclusive of 9 subjects, more than 200 journals)

Providing a 24-hour high-quality service

User-friendly online submission system

Fair and swift peer-review system

Efficient typesetting and proofreading procedure

Display of the result of downloads and visits, as well as the number of cited articles

Maximum dissemination of your research work

Submit your manuscript at: http://papersubmission.scirp.org/ 